\title{
Social inequalities: theories, concepts and problematics
}

\author{
Renato Miguel Carmo ${ }^{1}$ (D)
}

Received: 11 April 2021 / Accepted: 16 April 2021

(o) The Author(s), under exclusive licence to Springer Nature Switzerland AG 2021

\begin{abstract}
This article aims to present a concise perusal of the different approaches developed in the study of social inequalities and in the relationships that they establish with manifold social processes and problems. The text does not intend to be exhaustive from the theoretical point of view, but rather to present an overview of the analytical complexity of the inequalities systems and demonstrate that they should be tackled in a multidimensional, systemic and multiscale perspective.
\end{abstract}

Keywords Inequalities $\cdot$ Social theory $\cdot$ Public policy

\section{Introduction}

In the late 1970s, Amartya Sen delivered a lecture entitled "Equality of What?" in which he argued for the need to reshape the contemporary approaches to the processes of production of inequalities, towards the conceptualisation of a multidimensional vision that considers other aspects and variables which, at that time, were not incorporated in the majority of the analyses (Sen, 1980). It is along these lines that he put forward the concept of capability in the perspective of human development, and which underlies the annual reports published since 1990 by the United Nations Development Programme (UNDP).

The central idea substantiating the reports and various composite indices that have been constructed in this context over the past three decades is that of considering development and inequalities as multidimensional processes, where it is not analytically satisfactory to focus only on the economic dimension nor on conventional economic indicators, such as Gross Domestic Product per capita. Indeed, the challenge posed by Sen triggered great debate and discussion not only within the scientific milieu, but also in the political field and in the public space in general. This raises various questions on how we should analytically envisage and work on the topic of social inequalities and equality policies. This brief article endeavours to

Renato Miguel Carmo

renato.carmo@iscte-iul.pt

1 ISCTE - University Institute of Lisbon, Lisbon, Portugal 
make a concise perusal of the different approaches developed in the study of social inequalities.

\section{Multidimensional and systemic inequalities}

One of the sociologists who has most explored the concept of multidimensionality from the theoretical point of view is Göran Therborn who, in a book published in 2006, defines social inequalities as follows: «inequalities are differences that we consider unjust. Inequality is a negation of equality. Behind a perception of inequality there is a notion of injustice, a violation of some equality» (Therborn 2006, p. 4).

Thus, in the author's understanding, inequalities are by nature multidimensional and, for this reason, are not circumscribed merely to a sector of society (such as the economy, education, health, etc.), nor to a single resource or type of capital, following the conception by Pierre Bourdieu (2010 [1979]). According to this French sociologist, social actors unequally and more or less strategically mobilise an array of capital at their disposal: economic capital (wealth, income, property), cultural capital (educational qualifications, cultural practices, domination/mastery of the symbolic) and social capital (social networks and the belonging to certain clubs and associations). In this perspective, the social space is notoriously unequal as it is constituted and reconfigured based on the dynamics of social conflict and struggle in access to, possession and strategic mobilisation of distinct resources. Thus, we are dealing with a space of structured relationships leveraged by dominant and subaltern social positions according to the type and magnitude of the appropriated and activated capital.

The two sociologists share the idea that inequalities intercept in a relational way with respect to the causes and their effects. Along these lines, Therborn $(2006,2013)$ proposes that there are three major types of inequalities. Vital inequalities generally taken to mean the inequalities regarding life, health and death. These are expressed in indicators such as life expectancy at birth or infant mortality rate, which are used to comparatively analyse inequalities between populations or to analyse evolutions over time. This type of inequality is not circumscribed to a merely biological dimension as the very notion of vital or vitality incorporates factors of social, economic and even cultural order, that vary according to the geographic context and the level of human development unequally distributed between and within countries and regions (Costa 2012). In any case, in Therborn's understanding, this type of inequality refers to human beings as living organisms who experience a differentiated set of vulnerabilities in terms of their health and physical and mental well-being that, in turn, depend on a set of socially produced conditions with starkly unequal institutional and organisational responses (for example, in terms of the quality and comprehensiveness of the public health services, among others).

Another major type is resource inequalities that identify the unequal distribution of resources (social, economic and cultural). More specifically, they include dimensions such as inequalities of income and wealth, schooling and professional qualification, cognitive and cultural skills, hierarchical position in organisations and access to social networks (Costa 2012). Human individuals are viewed and framed 
as social actors who, according to Bourdieu's conception, strategically and relationally appropriate and mobilise a differentiated set of varied capital in the social space.

The last type refers to existential inequalities, meaning the unequal recognition of human individuals as persons. In this case, the focus is on the inequalities arising from oppressions and restrictions to individual and/or collective freedom, discriminations, stigmatisations and humiliations, illustrated by phenomena such as patriarchy, slavery or racism (Costa 2012). These embody an objective nature, in that they can be examined based on certain indicators, but, at the same time, they point to elements linked to the social construction of subjectivities and to the way that individuals perceive and experience a series of discriminations and injustices to which they are subjected.

As is evident, reciprocal relationships are established between these three major types of inequalities and, accordingly, it could be said that this approach is harmonious with the idea of Intersectionality. According to Sofia Aboim, "the theory of intersectionality, currently dominant in the analyses of gender relations, proposes, as advanced by Hill Collins (2019, p. 151), an analysis that affirms that systems based on race, social class, gender, sexuality, ethnic identity, nation and age mutually form the constructive features of social organisation" (Aboim 2020, p. 131). In this sociologist's thinking, Therborn's approach establishes theoretical and analytical connections with the perspective of Intersectionality.

The dynamics of interception tend to form systems (Bhir and Pfefferkorn 2008) or regimes of inequality (Piketty 2020) that are reproduced and perpetuated in the social space (Bourdieu 2010 [1979]). As Frederico Cantante states, "the systematicity of inequalities also implies that various types of inequality (economic, educational, housing, health) mutually interact and combine according to particular intensities and chain reactions, where certain inequalities tend to hierarchically condition others" (Cantante 2019, p. 36).

Following this same line of reasoning, Piketty (2020) proposes the notion of an inequality regime which incorporates a necessarily complex process of social construction, but also political and ideological, in which a series of discourses and institutional arrangements gradually crystallise to structure and justify the level of economic, social and political inequalities attained in a given society. Thus, the intersection and the multidimensionality of inequalities generate cycles, more or less vicious and enduring, of accumulated social vulnerabilities and disadvantages, that tend to affect social categories differently, particularly incident on the deprived classes and the more socially discriminated groups, thus further strengthening the mechanisms of social polarisation.

One of the books that most effectively attempted to give substance to the concept that inequalities are systemic and related to a series of social problems, entitled The Spirit Level (Wilkinson and Pickett 2009). This study correlates income inequality with the confidence level within societies, life expectancy, child mortality, health and obesity, the educational performance of children, homicides, among other indicators. The authors construct a composite index of "health and social problems" compiled using 10 basic indicators and identify a strong relationship between this index and the existing degree of economic inequality in each country (the analysis focuses on developed countries). The book advocates that the more egalitarian 
societies almost always operate better. In a certain way, they are more qualified and able to deal with risks and vulnerabilities in a manner providing enhanced conditions enabling people to achieve their individual aims.

\section{Inequalities: categories and social positions}

In view of the approaches referred to above, it is important to consider that inequalities are also associated with the constitution and assignment of social categories. To a large extent, it is through the reification of these categories that the processes of production and reproduction of inequalities are conveyed and activated, both at the individual and at the group level and at the institutional level. According to António Firmino da Costa, categories are generally constituted "as socially shared cultural standards", "as the way to understand the world, in particular the social world", "as instruments par excellence of social action" and, finally, "as subject to social transmission". These are comprehended and internalised through processes of socialisation, in the framework of deemed socialisation institutions, like the family and school (Costa 1998, pp. 68-69).

Following Charles Tilly (2005), the production of categorisation develops around four modes or situations fostering social inequality: via encounter among previously separate social groups that, upon coming into contact, develop symbolic forms of reciprocal categorisation; by the imposition of categories that discriminate against sets of individuals, purposely setting them apart from other social groups; by negotiation of boundaries, practices and interpretations, between individuals and groups in interaction; and by transfer of these categories, boundaries and relationships, from certain contexts and groups to others (Costa 2012).

The social construction of categories tends to be measured by complex processes that are difficult to capture through merely quantitative statistical and analytical indicators. Indeed, its analysis requires the simultaneous use of qualitative methods of intensive nature in order to properly grasp the procedural and relational dynamics that structure the formation of deeply rooted behavioural patterns (in the form of prenotions or stereotypes) transmitted from one group to the next or from one generation to the next.

Once again, we draw on the contribution of Göran Therborn (2006, 2013), who identifies a set of profound and structural social processes generating a large part of the inequalities, which have been systematically studied by different theoretical schools and their research teams. Actually, this boils down to the evincement of four concepts that are relatively established in the social sciences. Hence, the concept of exploitation, at least partially reminiscent of the Marxist or neo-Marxist perspective, that the sociologist takes to refer to the generation of inequalities by virtue of the asymmetric appropriation of some products and assets to a large extent produced by others (Costa 2012). In that vein, Erik Olin Wright considers that exploitation is based on the idea of antagonistic interests occurring when the gain of one actor, or a set of actors, excludes others from gaining the same advantage (Wright 1994). 
The second process describes the forms of exclusion and refers, according to Therborn, to the generation of inequalities by the effect of selective restrictions that certain groups impose on the access of others to resources and opportunities (Costa 2012; Therborn 2013). The neo-Weberian perspective has developed this approach with a view to identifying processes of social closure that, following Frank Parkin (1979), aim to keep a firm grip on the control of resources and ensure the distancing of a particular set of individuals and/or groups from the possibility of benefiting from certain opportunities in life. In turn, this idea of closure is also linked to the process of distanciation (third) which means the generation of inequalities as a result of processes of competition or rivalry in systems of interdependence, namely markets or quasi-markets (Costa 2012; Therborn 2013). Finally, the fourth, hierarchisation, signifies the generation of inequalities via the effects of institutionalisation of positions of superiority and inferiority in formal organisations (Costa 2012; Therborn 2013).

As noted above, the identified processes and mechanisms have been studied through various theoretical currents and methodological approaches, but whose focus of analysis concentrates on the concept of social class and on the modes of stratification and social reproduction. There are various formulations for the classification of operationalisation and configuration of class categories (or positions). In the sociological research carried out in Portugal, particular use is made of the ACM typology, named after its authors, which consists of a socio-professional indicator of class positions, constructed based on two key variables, "profession" and "situation in the profession". ${ }^{1}$ According to António Firmino da Costa and Rosário Mauritti, this typology embodies a series of conceptual and operational properties: "allowing for comparison with other benchmark classifying typologies"; "enabling the use of empirical data derived both from institutional statistics and research surveys"; "this is a very compact classification, permitting the analysis of large-scale comparisons, in particular international"; "able to give rise to finer versions of the typology, applicable to specific analytical problems and empirical contexts" (Costa e Mauritti 2018, p. 112).

The use of this typology has not only persisted in sociological studies on the social composition and recomposition of societies, but also framed an elasticity that can be adjusted to various sociospatial scales (local, regional, national and transnational). This is illustrated, for example, by the research on classes and the appropriation of social capital at the scale of the European transnational space (Carmo

\footnotetext{
1 The most recent configuration of the ACM typology is composed of the following class categories: "Employers and executives are employers or directors at private companies or in the public administration. They may be recruited from any of the groups in the occupational structure. Private Professionals are self-employed and very qualified in certain specialised professions, such as lawyers, architects, and so on. Professionals and managers are employees in upper or mid-level intellectual, scientific and technical jobs. They are different from the previous category essentially because they are not self-employed. Selfemployed workers work on their own account without employees in administrative or similar occupations in services and commerce. They include craftsmen and similar workers, farmers and qualified workers in agriculture and fishery. Routine employees are administrative and similar personnel, service employees and salespeople. Industrial workers are manual workers employed in less qualified occupations in construction, industry, transports, agriculture and fishery (Carmo and Nunes 2013, p. 378).
} 
and Nunes 2013), where the analysis of the findings of the European Social Survey (2008 round) revealed dynamics of social closure between the dominant classes in relation to the subaltern.

\section{Spatial and multiscale inequalities}

Although Therborn's typology does not frame territorial inequalities as a crucial element for the study of inequalities, we can consider them in the aforesaid dimensions. ${ }^{2}$ Sociospatial differentiation is, in many cases, a determinant factor for the unequal distribution of resources. This is confirmed by the mere comparison of urban spaces with a large part of the rural zones. Territories can be highly discriminatory, as is the case with the level of segregation to which certain run-down neighbourhoods in the midst of cities are relegated. Likewise, they can be decisive for the lesser or greater vitality of populations, as demonstrated by the major discrepancies observed between countries, based on the human development index (UNDP 2019).

It is increasingly more important to consider the territories and their many scales in the study of social inequalities. In Branko Milanovic's understanding, the current process of globalisation has led to growing inequality between countries and the continental regions in which they are located. Thus, in his analysis of international and global income inequalities, Milanovic (2012) distinguishes three fundamental concepts. Inequality "concept 1", or international inequality without populationweighting, and inequality "concept 2 " or international inequality with populationweighting (countries' population sizes are taken into account). Both refer to inequalities between countries, calculated across GDP or mean incomes obtained from national household surveys of all countries in the world. Inequality "concept 3", or global inequality, where "unlike the first two concepts, this one is individual-based: each person, regardless of her country, enters in the calculation with her actual income (Milanovic 2012, p. 4). This, therefore, refers to inequalities between individuals, at a worldwide scale, with its primary source of information being direct population surveys (individuals and household groups).

The economist advocates that the direction of the diachronic evolution of inequalities, since the second half of the twentieth century, varies, at a worldwide scale, according to the concept in question. Thus, if we compare inequalities between countries (concept 1), it is clear that they have increased consecutively. But if we take into account the population-weighting (concept 2), a stabilisation of inequalities is observed, due to the positive impact of the increased disposable income in the Chinese and Indian populations, which has primarily taken place over the last two decades. However, the increased average income observed in countries such as China that has contributed to reduce the population in a situation of absolute poverty does not mean that the inequalities within this country are diminishing. To the contrary, according to the data provided by the actual author (Milanovic 2016, 2012), firmly corroborated by a series of reports (OECD 2011, 2015; ADB 2012),

$\overline{2}$ This section is based on Carmo (2014, pp. 134-138). 
income inequalities between regions in China have grown considerably, especially between the rural and urban areas. In turn, according to concept 3, the inequalities are revealed to be at a higher level, which has remained more or less constant over the last decades.

This analytical and conceptual distinction proposed by Milanovic throws light on the importance of multiscale approaches for the study of inequalities, in which the same indicator could, for example, cover different historical evolutions and distinct orders of magnitude according to the analytical perspective in question. In a book entitled World City, the geographer Doreen Massey (2007) warned us precisely on the increased inequalities associated with the impact of economic activity and, most particularly, the financial activity of the City of London, on the rising regional disparities and imbalances affecting the United Kingdom. According to this author, social disparities have skyrocketed not only within London metropolitan area, but have also increased in relation to other cities and regions of England. This two-faceted trend (interregional and intraregional) of growth of inequalities has its epicentre, albeit not exclusively, in the megacities, that have become extremely prominent in the global economy. Indeed, many of these territories have undergone remarkable demographic growth that corresponded to an increase of their employment catchment areas and labour supply, in addition to the expansion of increasingly more complex, diversified and asymmetric job markets.

These trends were captured by a series of approaches carried out in the late 1990s, which pointed to the consequences of globalisation and the development of new information and communication technology in the social reconfiguration and dualisation taking place in labour markets (Castells 2000; Sassen 2000). More recent studies published by international organisations (OECD 2011, 2015; UNDP 2019) refer to the increased interregional inequalities, namely between rural and urban zones, in particular in the economies of the emerging countries. These and other approaches have confirmed the relevance of envisaging what could be considered as inequality "concept 4", arising from the interdependence between social inequalities and territorial inequalities (Carmo 2014). For such, it is fundamental to consider not only the multidimensionality but also the multiscale nature of inequalities.

\section{Inequalities, social mobility and capabilities}

As highlighted above, many of the processes generating inequality persist over time, but also have a reproductive effect rippling throughout various generations. In this regard, social reproduction is an objective structural mechanism, where, for example, it can be measured that the children of wealthier and more qualified parents tend to have educational advantages (more academic success and less early school leaving) over students coming from more deprived families, or where it can be observed that social mobility depends to a large extent on family social background which constrains ascending or descending trajectories. A recent report published by the OECD (2018) studies intergenerational mobility, comparing the social position attained by an individual at a given moment with the corresponding position of the parents (social origin), and demonstrates that the social ladder of a large part of 
contemporary societies is relatively broken. Nevertheless, the truth is that in societies such as the Portuguese, the likelihood of a blue-collar worker's child becoming a manual labourer is still very strong.

On the other hand, social reproduction is simultaneously incorporated and legitimated subjectively, as clearly demonstrated by Bourdieu, who stressed that life expectancies are partially determined by the individual's social position and origin. For example, in the field of education, 'winning' or achieving good grades can have a very different significance for a student coming from a family with highly qualified parents compared to another coming from a low-qualification working class environment. The former could be 'fighting' to get into a highly valued university course, like medicine or aerospace engineering, while the latter 'fights' just to have access to higher education.

Many socioeconomic and sociocultural conditions are, in social terms, partially inherited and affect the opportunities and expectations of peoples' lives (playing in various sectors and spheres of social and economic life). Thus, a relationship is established between the outset social inequality level (inequality of outcome) and the real possibilities of upward social mobility (equality of opportunity). The lower the degree of interference of the inherited factors in the content and mechanism of this relationship, the higher the individuals' real possibilities of appropriating the best opportunities of life irrespective of their social origins (Carmo 2009). As stated by Anthony Atkinson, “inequality of outcome among today's generation is the source of the unfair advantage received by the next generation. If we are concerned about equality of opportunity tomorrow, we need to be concerned about inequality of outcome today" (Atkinson 2015, p. 11). This means that if inequalities are reproduced generationally, this fact compromises the notion of "equal opportunities as a meritocratic ideal [and] the idea of the loss of influence of social structures in the definition of the trajectories of individuals" (Cantante 2019, p. 36).

In order to (re)establish the mechanisms of upward social mobility, it is fundamental for States, societies and economies to invest, promote and facilitate access to (and use of) a differentiated set of social protection and public service systems (education, health, justice, social security, etc.) with a view to increasing intra and intergenerational social justice (Carmo et al., 2018). In the conception inspired by the work of John Rawls (2001 [1971]), it is important to assure equitable distribution based on the overall efficiency of the redistributive and provision system, enabling the lower income members of society to improve their living conditions (referred to as "primary goods").

However, although the redistribution of income and other resources generated by the economy is a necessary condition to ensure increased social cohesion, it is not sufficient to strive for full social justice. In order to become a sufficient condition, the redistributive policy should interact with other polices that affect individual and collective capabilities (Barata and Carmo 2015). Or, as argued by Amartya Sen, peoples' real opportunity to strive towards their goals depends not only on the primary goods possessed and accessed by each person, but also on the personal characteristics considered relevant that enable converting primary goods into personal skills that promote the actual goals (Sen 2003 [1999]). 
The Human Development Report of 2019 (UNDP 2019) focused on the topic of inequalities, puts forward three strong ideas, that we should: (a) envisage inequalities beyond income and wealth, understanding that although these dimensions are relevant, it is crucial to deepen more comprehensive approaches able to frame other aspects of human development; (b) go beyond mere averages based only on unidimensional analyses; and (c) project beyond the present time, covering the evolution and reduction of inequalities up to the twenty-second century. Along these lines, the report proposes a more complex conception of the forms of capacity-building, distinguishing basic capabilities associated with the eradication of extreme deprivation, from enhanced capabilities that increase the modes of individual and collective agency towards providing people with enhanced conditions to promote and achieve their own goals. Examples of enhanced capabilities are accessing high-quality health, achieving higher education degrees, using cutting edge technology and incorporating greater resistance to unexpected shocks and risks.

\section{Final remarks}

The question raised by Amartya Sen "equality of what?" represented and still represents an enormous theoretical and conceptual challenge, but also empirical. As we have seen in this brief article, inequalities necessarily imply multidimensional and systemic processes where they cross creating dynamics of intersectionality; they are produced by complex formulations of categorisation generating mechanisms of social closure and exclusion; they should be framed by territorial dynamics and in different analytical scales; they have considerable impacts on social mobility trajectories and on forms of social reproduction; and they constitute regimes that are also produced and reproduced in the realms of ideology and political struggle. For these reasons, inequalities are neither reduced nor combated merely through simple and unidimensional measures directed at one or another sector, or at a specific social group. Indeed, in order to have notable impacts that are durable over time, equality policies should be of a multidimensional, systemic, multiscale magnitude and foster capacity-building. This is an immense challenge for countries and for national and international institutions. But only by facing this enormous challenge with determination will it be possible to appropriately, and via political action, answer the question posed by Sen.

Acknowledgements This work was developed within the project EmployALL-The employment crisis and the Welfare State in Portugal: deterring drivers of social vulnerability and inequality, funded by the Fundação para a Ciência e Tecnologia (PTDC/SOC-SOC/30543/2017).

Data availability Data sharing not applicable to this article as no datasets were generated or analysed during the current study.

\section{Declarations}


Conflict of interest The author declares no competing interests.

\section{References}

Aboim S (2020) Covid-19 e desigualdades de género: uma perspetiva interseccional sobre os efeitos da pandemia. In: Carmo RM, Tavares I, Cândido AF (eds) Um Olhar Sociológico sobre a Crise Covid19 em Livro. Observatório das Desigualdades, CIES-Iscte, Lisbon, pp. 130-148: https://www.obser vatorio-das-desigualdades.com/2020/11/29/umolharsociologicosobreacovid19emlivro

ADB-Asian Development Bank (2012) Outlook 2012. Confronting Rising Inequality in Asia s.1., ADB. Atkinson AB (2015) Inequality: what can be done? Harvard University Press, Cambridge

Barata A, Carmo RM (2015) O Futuro nas Mãos: de Regresso à Política do Bem-Comum. Tinta-daChina, Lisbon

Bhir A, Pfefferkorn R (2008) Le system des Inégalités. La Découverte, Paris

Bourdieu P (2010[1979]) A Distinção: uma crítica social da faculdade de juízo. Edições 70, Lisbon.

Cantante F (2019) O Risco da Desigualdade. Almedina, Coimbra

Carmo RM (2009) Coesão e capital social: uma perspetiva para as políticas públicas. In: Veloso L, Carmo RM (eds) A Constituição Social da Economia. Mundos Sociais, Lisbon, pp 197-230

Carmo RM (2014) Sociologia dos Territórios: Teorias. Estruturas e Deambulações, Mundos Sociais, Lisbon

Carmo RM, Nunes N (2013) Class and social capital in Europe: a transnational analysis of the European Social Survey. Eur Soc 15(3):373-387

Carmo RM, Rio C, Medgyesi M (eds) (2018) Reducing inequalities: a challenge for the European Union? Palgrave Macmillan, Basingstoke

Castells, M (2000) The information age. Economy, society and culture. $2^{\mathrm{a}}$ ed., Blackwell Publishers, Oxford.

Costa AF (1998) Classificações Sociais. Leituras: Revista da Biblioteca Nacional 3(2):65-75

Costa AF (2012) Desigualdades Sociais Contemporâneas. Mundos Sociais, Lisbon

Costa AF, Mauritti R (2018) Classes sociais e interseções de desigualdades: Portugal e a Europa. In: Carmo RM et al (eds) Desigualdades Sociais: Portugal e a Europa. Mundos Sociais, Lisbon, pp $109-129$

Hill Collins P (2019) Intersectionality as critical social theory. Duke University Press, Durham

Massey D (2007) World city. Polity Press, Cambridge

Milanovic B (2012) Global income inequality by the numbers: in history and know. World Bank Policy Research Working Paper 6259: 1-28

Milanovic B (2016) Global inequality. Cambridge, Belknap

OECD (2011) Divided we stand. Why inequality keeps rising. OECD Publications, Paris

OECD (2015) In it together: Why less inequality benefits all. OECD Publications, Paris

OECD (2018) A broken social elevator? How to promote social mobility. OECD Publications, Paris

Parkin F (1979) Marxism and class theory: a bourgeois critique. Tavistock, London

Piketty T (2020) Capital and ideology. Cambridge, Belknap

Rawls J (2001) [1971] Uma Teoria da Justiça, 2nd edn. Editorial Presença, Lisbon

Sassen S (2000) Cities in a world economy. Pine Forge Press, Thousand Oaks

Sen A (1980) Equality of What? In: McMurrin S (ed) Tanner lectures on human values, vol I. Cambridge University Press, Cambridge

Sen A (2003) Desenvolvimento como Liberdade. Gradiva, Lisbon

Therborn G (ed) (2006) Inequalities of the world new theoretical frameworks: multiple empirical approaches. Verso, London

Therborn G (2013) The killing fields of inequality. Polity Press, Cambridge

Tilly C (2005) Historical perspectives on inequality. In: Romero M, Margolis E (eds) The Blackwell Companion to Social Inequalities. Blackwell, Malden, pp 15-30

UNDP (2019) Beyond income, beyond averages, beyond today: inequalities in human development in the 21st century. Human Development Report 2019.

Wilkinson R, Pickett K (2009) The spirit level. Why more equal societies almost always do better. Allen Lane, London 
Wright EO (1994) Análises de classes, história e emancipação. Revista Crítica de Ciências Sociais 40:3-35 